\title{
ELITES LOCALES Y ECONOMÍA POLÍTICA EN LA MESOAMÉRICA POSCLÁSICA: EL CASO DE MOLANGO (SEÑORÍO DE METZTITLÁN)
}

\author{
POR \\ ROSSEND ROVIRA MORGADO \\ Departamento de Historia de América II (Antropología de América) \\ Universidad Complutense de Madrid
}

Ante el panorama político de constantes fluctuaciones en el juego de lealtades y subordinaciones señoriales que definió la Mesoamérica del Horizonte Posclásico Tardío (1350-1521 d.C.), las elites locales pudieron haber mostrado diversos niveles de dependencia hacia diferentes entidades políticas hegemónicas. En el presente artículo focalizamos nuestro estudio en el caso de la localidad mexicana de Molango de Escamilla (Estado de Hidalgo). Los datos etnohistóricos que aportamos sugieren que Molango — dependiente del señorío de Metztitlán durante la época prehispánica - muestra fuertes vinculaciones con el próximo señorío de Huejutla y con el Imperio de la Triple Alianza. Proponemos que esta ambivalencia de relaciones políticas se inserta en la necesidad de mantener el control de recursos económicos estratégicos y del acceso a los canales de abasto comercial.

Palabras clave: Elites locales, Molango, economía política, obsidiana, sal, sistema-mundo de la Mesoamérica Posclásica.

\section{INTRODUCCIÓN}

Durante los siglos previos a la llegada de los primeros occidentales al territorio que denominamos como Mesoamérica sus sociedades experimentaron un profundo cambio. Diversos investigadores han incidido en el hecho de que factores de muy diversa índole impulsaron dicho fenómeno hacia el 1150-1200 d.C. en esta área cultural. De entre ellos, la articulación de las pequeñas unidades sociopolíticas que llamamos en lengua nahuatl altepemeh (sing. altepetl) en una compleja dinámica de interacción, vinculación y subordinación hacia entidades político-territoriales de gran escala parece haber sido 
de los más importantes ${ }^{1}$. Aunado a este fenómeno de fragmentación y concentración modular de unidades políticas, la Mesoamérica Posclásica asistió al desarrollo de vastas redes de comercio a larga distancia. El aumento demográfico que se detecta en ciertas zonas de Mesoamérica - como el México Central- 2 conllevó un incremento en el consumo de bienes tan necesarios como la sal, la obsidiana, la cerámica utilitaria o los tejidos. De este modo, el comercio cubrió necesidades domésticas que interactuaban con un sistema de abasto de escala internacional ${ }^{3}$. En el sistema comercial a larga distancia de la Mesoamérica Posclásica estos bienes de subsistencia circulaban juntamente con productos de lujo, como pieles y plumas preciosas, piedras verdes, cacao, copal, orfebrería de oro, plata o cobre y objetos de turquesa. A parte de ser artículos que podían ser requeridos por el tributo de las elites ${ }^{4}$, éstos mismos se podían adquirir en ciertos mercados —o tianquizqueh - que caracterizaban la vida económica pública de las sociedades mesoamericanas del Horizonte Posclásico. Tal parece haber sido el caso que encontramos documentado en México-Tlatelolco, Cholula o Cozumel ${ }^{5}$. No obstante, no podemos olvidar que las restricciones tecnológicas relativas al transporte en Mesoamérica limitaban el movimiento masivo de ciertos productos ${ }^{6}$. En este sentido, el acceso a las principales rutas comerciales, así como a ciertos centros de intercambio internacional, podía asegurar el abastecimiento de mercancías de necesidad básica $\mathrm{y}$ de prestigio. Mercaderes especializados en el comercio a larga distancia como los pochtecah del Valle de México, los ppolomob' yucatecos y los maya-putum de Tabasco-Campeche viajaban a Xicalanco (Costa del Golfo), Xoconochco (Costa del Pacífico en Guatemala), la Bahía de Chetumal (Belice), Nito y Naco (Golfo de Honduras), Coaixtlahuaca (Oaxaca, México) o Huejutla (Hidalgo, México) con motivo de conseguir estos preciados bienes ${ }^{7}$. Hemos de presuponer que en estos enclaves comerciales de encuentro multiétnico los mercaderes locales negociarían con los comerciantes extranjeros. Todo ello es sintomático de la existencia de una economía compleja altamente

1 Rojas, 21 (Madrid, 1991): 145-169. Carrasco, 1996: 589-590. Lockhart, 1999: 160. Smith y Berdan, 2000: 285. Smith, 2005: 420.

2 Michael E. Smith (2003a: 57-59) plantea la posibilidad de un rápido y sostenido crecimiento poblacional en el Altiplano Central de México durante los dos últimos siglos prehispánicos que habría alcanzado su techo en 4 millones de habitantes hacia 1519.

3 Berdan y Smith, vol. XXV/099 (Zamora [México], 2004): 19-20.

4 Consúltese Carrasco y Broda (eds.), 1978.

5 Durán, 1971: 278. Díaz del Castillo, 1999 [1575]: 260-263. Cortés, 2000 [1520]: 139-140. De Landa, 2001 [1566]: 97. Muñoz Camargo, 2001 [1585].

6 Hassig, 1985: 56, 128-129.

7 Berdan et alii, 2003: 101, 103-104. 
comercializada para este momento. Los mercados, los diferentes tipos de tratantes y los diversos medios que fungían como moneda de cambio ${ }^{8}$ eran ejes esenciales en su funcionamiento.

En consecuencia, podemos apreciar que las elites locales de las sociedades de la Mesoamérica Posclásica mostraron una clara preocupación por salvaguardar ciertos aspectos de la economía política, tales como las tasas y rentas particulares, el tributo o el comercio. Este hecho las llevó a interactuar en muy diversos niveles con unidades sociopolíticas mayores o inferiores. Dicha arena de actuación política promovió un intrincado marco de alianzas y lealtades entre señores ${ }^{9}$. En un mundo en constante crecimiento demográfico como era Mesoamérica en los siglos XV y XVI con anterioridad al proceso de Conquista los sistemas de aprovisionamiento y las esferas de consumo fueron puntos clave para entender las estrategias de actuación económica. Las elites locales maniobraron políticamente en congruencia con sus propias necesidades de mantener o acceder a diversas fuentes económicas. Un ejemplo atractivo de lo expuesto lo constituye el señorío de Metztitlán y uno de sus señoríos dependientes: Molango.

\section{EL DEBATE INICIAL: LA CARACTERIZACIÓN DEL SEÑORÍO DE METZTITLÁN Y LA UBICACIÓN DE MOLANGO}

El antiguo señorío de Metztitlán ha sido un campo fecundo para la moderna investigación arqueológica y etnohistórica en torno a la Mesoamérica prehispánica ${ }^{10}$. Este hecho se debe al carácter de independencia que mostró ante la Triple Alianza liderada por México-Tenochtitlan en el Posclásico Tardío y al consecuente déficit de noticias que tenemos sobre él. Se trata de un territorio localizado en la zona centro-norte del moderno estado mexicano de Hidalgo. Desde el punto de vista geológico y medioambiental, ocupa diversos pisos altitudinales que bordean y circunvalan una profunda fractura en la Sierra Madre Oriental que desciende vertiginosamente hasta los 1500-1200

8 Diversas fuentes etnohistóricas mencionan el uso de granos de cacao, canutillos de oro, diferentes tipos de mantas de algodón (quachtli) y hachuelas metálicas en forma de $\mathrm{T}$ como medios proto-monetarios en la economía de la Mesoamérica Posclásica. Para explorar con mayor profundidad dicho aspecto consúltese la obra del Dr. J. L. de Rojas La moneda indígena en la Nueva España en el siglo XVI. Publicaciones de CIESAS, México DF, 1998.

9 Hoekstra, 1990: 75-76.

10 Barlow, 1949. Davies, 1968: 29-61. Lameiras, 1969. Osborn, 1970. Gerhard, 1972: 183-187. Smith, 1996: 140-141. Carrasco, 1996: 14-15 Contreras, 1997. Lorenzo, 2001. Smith y Berdan (eds.), 2003. Álvarez Palma y Cassiano, en vigor. 
m.s.n.m. La red hidrográfica que nutre a esta cuenca de tipo sub-tropical está integrada por tres ríos principales: el Amajac, el Almolón y el Venados. Los dos primeros forman parte de un régimen endorreico, puesto que se hallan estrechamente relacionados con las lagunas de Metztitlán y de Atezca. Por su parte, el río Venados discurre a lo largo de toda la Vega de Metztitlán con una orientación SE-NO, convirtiéndose en afluente del cercano río Pánuco. Este tipo de características ecológicas dotaron a la zona de Metztitlán con la posibilidad de tener acceso a una compleja complementariedad económica integrada por recursos naturales explotables tanto en pisos de clima alpino o frío como aquéllos de tipo templado y sub-tropical.

La temprana conquista de Metztitlán se efectúa en 1524, aunque fue precedida de intentos frustrados de pactismo entre las elites indígenas y los nuevos señores castellanos. Con referencia a este suceso, Hernán Cortés nos comenta lo siguiente:

(...) me enviaron [Metztitlán y Tototepec] por sus súbditos y vasallos; y yo los recibi en el real nombre de vuestra majestad, y por tales quedaron y estuvieron siempre, hasta después de la venida de Cristóbal de Tapia, que con los bullicios y desasosiegos que en estas otras gentes causó, ellos no solo dejaron de prestar la obediencia que antes habian ofrecido, mas aun hicieron muchos daños en los comarcanos a su tierra, que eran vasallos de vuestra católica majestad, quemando muchos pueblos y matando mucha gente, (.... $)^{11}$

Con posterioridad a la consecuente reducción militar a la cual las huestes castellanas sometieron a los metzcah, el propio Marqués del Valle inició el reparto de encomiendas a los conquistadores Miguel Díez de Aux, Alonso Lucas y a su pariente Andrés de Barrios ${ }^{12}$. De forma paralela, se efectuó la llegada de los primeros agustinos a Metztitlán, la cual se formalizaría en 1536-1538 con la construcción de la capilla de San Miguel y del convento de Nuestra Señora de Loreto en Molango ${ }^{13}$. La conducta abusiva que exhibió esta primera generación de encomenderos en torno a la utilización masiva de mano de obra indígena en la explotación minera de la cercana localidad de Ixmiquilpan promovió fuertes disturbios sociales que desembocaron en la realización de una visita real por parte de Don Diego Ramírez durante el año $1553^{14}$. Hemos de

11 Cortés, 2000 [1524]: 307.

12 Gerhard, 1972: 183-184.

13 Artigas, 1996. Merece la pena recordar que Fray Juan de Sevilla y Fray Antonio de la Roa inician la evangelización de la Sierra Alta en 1536. Éste último dirigió sus esfuerzos iniciales a erradicar los cultos prehispánicos de los metzcah. En Molango destruyó la imagen y el templo del venerado dios llamado Molan, lo que sugiere que esta localidad era un importante centro regional de peregrinaje en la época prehispánica tardía (Grijalva, 1926 [1620]: 124).

14 Contreras, 1997: 142-144. 
remarcar que desde 1531 la Corona había impulsado las primeras medidas de control institucional en Metztitlán mediante la creación de los corregimientos de Molango y Malila ${ }^{15}$. Aún así y con el despliegue de todo este aparato proteccionista, el dominio privado sobre la propiedad de bienes inmuebles, servicios personales y mano de obra fue un rasgo que definió Metztitlán a lo largo de toda la época virreinal. Prueba de ello lo aporta el hecho de que la localidad metzca de Chapulhuacán formó parte de los bienes patrimoniales de Doña Isabel de Moctezuma ${ }^{16}$.

Las fuentes etnohistóricas principales con las cuales aproximarnos a la organización de Metztitlán durante la época prehispánica son los Memoriales de Fray Toribio de Benavente «Motolinía», la Monarquía Indiana de Fray Juan de Torquemada, el Parecer sobre el modo que tenían de tributar los indios [de Metztitlán] en tiempos de su gentilidad, escrito en 1554 por Fray Nicolás de San Vicente Paulo, y la Relación de la Provincia de Metztitlán (1579), elaborada por el Alcalde Mayor Gabriel de Chávez. Este último documento histórico ha constituido de manera tradicional el punto de partida en las investigaciones acerca del antiguo patrón sociopolítico del Metztitlán prehispánico (Fig. 1):

«Este pueblo de Metztitlán fue cabeza de toda esta serranía, y señor de todos los pueblos que se incluyen, hasta confinar con la provincia de la Guaxteca, y permaneció siempre con este Señorio, hasta que vinieron los españoles y el Marqués del Valle, Don Hernando Cortés, la dividió y repartió en la forma que hoy está. Las provincias y pueblos que solía tener debajo su dominio y señorío son: la provincia de Molango y la provincia de Malila, que están en la Real Corona; la provincia de Tlachinoltícpac,... la provincia de Ilamatlan y Atlihuetzian, la provincia de Guazalingo... Todas estas provincias reconocían a esta cabecera de Meztitlán y acudian con gente de guerra y bastimientos a las fronteras, donde tenían gente de guarnición contra los mexicanos y las demás partes.» ${ }^{17}$

La Relación otorga un excesivo énfasis al territorio compacto y nucleado que presentaría el señorío prehispánico. Sus dominios se extenderían extremadamente hacia un norte resguardado de las hordas chichimecas por los fuertes militares de Xilitla y Xalpan (Jalpa, Querétaro). Sin embargo, la información que aporta la Relación debe ser sometida a un análisis interno riguroso y detenido, puesto que muchos datos relativos a las relaciones de poder o la organización geo-política no parecen prestarse tan fácilmente a una extrapolación directa con la época prehispánica. Durante el período 1524-1579 se producen

15 Ruiz de la Barrera, 2000: 51.

16 Gibson, 1964: 423. Gerhard, 1972: 184.

17 Acuña, 1986. 
Figura 1. Mapa de la Relación Histórico-Geográfica de la Provincia de Metztitlán

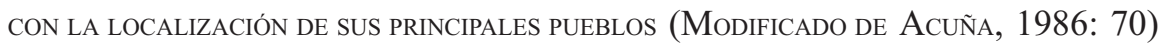

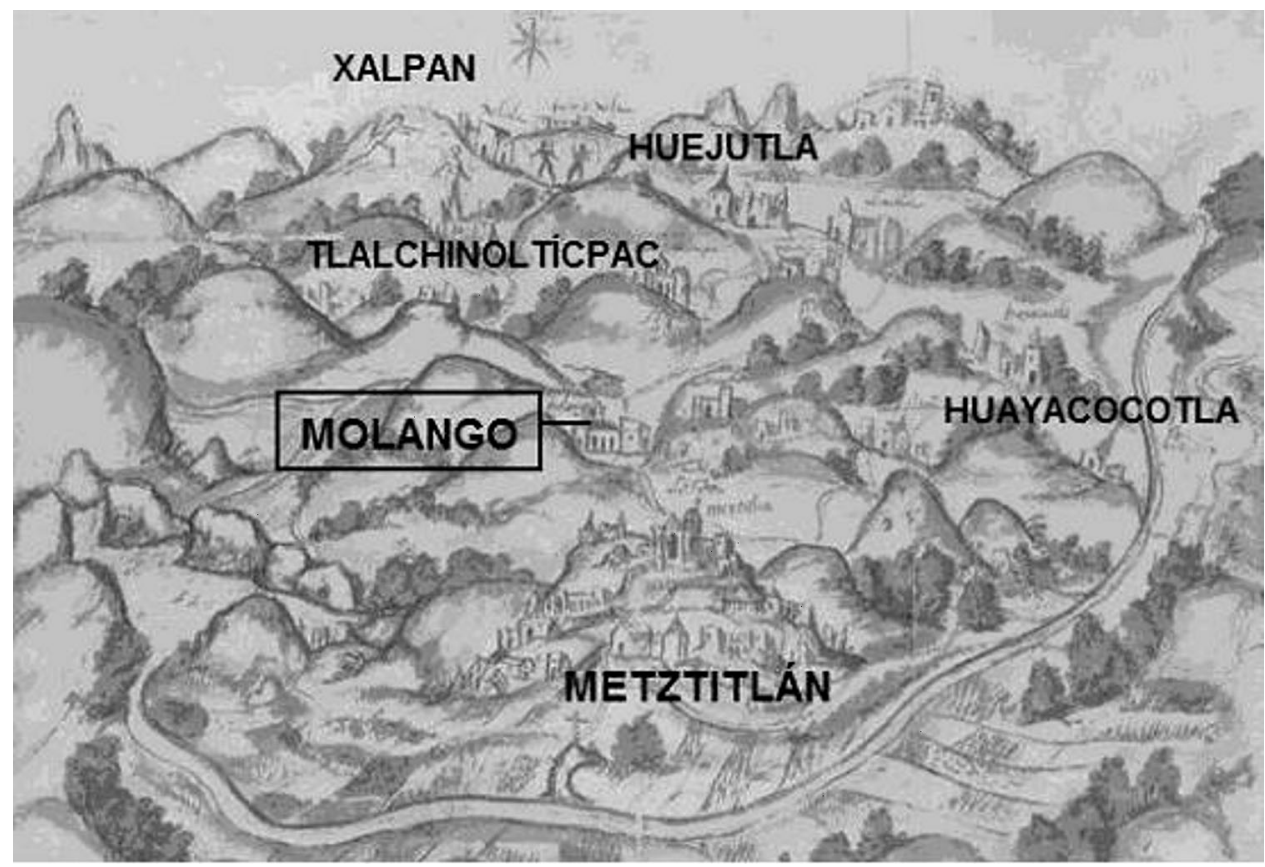

profundas transformaciones en Metztitlán asociadas a la Conquista, la re-organización del régimen de tenencias y propiedades sobre la tierra a raíz de las intrusiones castellanas - encomenderos y agustinos-, los fuertes virajes ocasionados en la economía política y en la explotación de la mano de obra disponible, el traslado de la capitalidad de la región a la recién construida villa de Metztitlán y el surgimiento de un nueva arena de actuación política para las elites indígenas locales. Todos estos fenómenos reiteran el carácter contemporáneo de lo redactado en la Relación y, al mismo tiempo, marcan un punto de distanciamiento en la historicidad de aquellos acontecimientos que presumiblemente tuvieron lugar en la época prehispánica tardía ${ }^{18}$. Nigel Davies, apoyándose en fuentes documentales más tempranas — como la Suma de Visitas de 1554-, establece que el señorío prehispánico de Metztitlán estuvo integrado por una confederación de cacicazgos locales centrados en un territorio mucho más menor al controlado por la Provincia de Metztitlán, de la cual la Rela-

18 Fernández y Garza, 2007. 
ción de 1579 sería su más fiel reflejo ${ }^{19}$. Hemos de presuponer que el grado de integración y de centralización político-territorial del señorío de Metztitlán fue débil y que tan sólo pudo establecer un dominio de carácter nominal en esta zona del México Central. Diversos señoríos locales podrían haber establecido una carrera competitiva por ostentar un cierto nivel de poder regional y tan sólo el señor de Metztitlán pareció haber dispuesto de un férreo carisma personal que posibilitó la transferencia regular de bienes y servicios hacia su territorio. Las dinámicas de competición faccional entre elites locales ${ }^{20}$ recibieron un nuevo estímulo tras las consecuencias ocasionadas con la Conquista. En este sentido, debemos recordar que los centros de poder metzca más importantes hacia 1524 - Tepatetipa y Malila - fueron perdiendo fuerza a lo largo de las décadas centrales del siglo XVI, puesto que el primero fue abandonado tras la Conquista y el segundo sufrió una fuerte amputación administrativa con el surgimiento del competitivo centro vecino de Lolotla en 1570 .

A todo ello ayudó el auge de un pequeño señorío subordinado a Metztitlán durante el Posclásico Tardío que en menos de cincuenta años se había convertido en el núcleo de un influyente corregimiento (1531), en el centro espiritual de los agustinos de esta zona (1536) y en la sede de una alcaldía mayor (1560): Molango.

Llegados a este punto, nos encontramos ante una controversia inicial al afrontar esta investigación: la identificación del Mollanco de las fuentes etnohistóricas con la moderna localidad de Molango de Escamilla (Estado de Hidalgo, México).

Nigel Davies sintetizaba perfectamente tal problemática:

Sobre Mollanco, estamos de acuerdo con [R. H.] Barlow, que es poco probable que sea el Molango actual a $25 \mathrm{~km}$. al noreste de Metztitlán, en vista de que hay otro Mollanco (Tecpan Mollanco), identificado por Melgarejo cerca de Izhuatlán de Madero (Melgarejo: 148) [en Veracruz]. Este otro Mollanco no cae dentro de lo que, según la Relación [de Metztitlán, 1579], era territorio de Metztitlán. No nos parece probable que los aztecas hubiesen conquistado el Mollanco cercano al norte de Metztitlán ${ }^{21}$.

19 Davies, 1968: 29-32.

20 Véase una definición preliminar del concepto de «faccionalismo político» aplicado al desarrollo histórico de las sociedades de la América prehispánica en Brumfiel y Fox (eds.), 1994: 3 .

21 Davies, 1968: 33-34. 
Cabe destacar que Molango aparece como una localidad sujeta a la provincia tributaria (calpixcayotl) de la Triple Alianza denominada Tziuhcóac, juntamente con esta misma cabecera, Ichcatlán, Cozcateuhtlan y Xocoyohcan ${ }^{22}$. R. H. Barlow (1949), N. Davies (1968) y P. Carrasco (1996) consideraron, pues, que el Molango sujeto a los poderes del Imperio de la Triple Alianza no podía corresponderse al pequeño señorío local vasallo de Metztitlán en la época prehispánica tardía. Sin lugar a dudas, este hecho se correlaciona con el paradigma teórico prevaleciente en las investigaciones sobre la naturaleza política tanto del llamado «Imperio Azteca» como del Estado en Mesoamérica hasta la década de $1990^{23}$. Bajo la perspectiva del materialismo histórico y del evolucionismo cultural, las formaciones imperiales de la Mesoamérica prehispánica forjaron poderosos Estados centralizados con fronteras político-territoriales claramente definidas. Sin embargo, el investigador Ross Hassig bautizó con el nombre de «Estado hegemónico» la organización sociopolítica que enmascararía el Imperio de la Triple Alianza en el México Central a inicios del siglo XVI ${ }^{24}$. Bajo esta denominación reconoció una compleja institución (huey tlahtocayotl) cuyas fronteras territoriales eran entendidas como límites o dominios muy volubles de clientelas señoriales. Así pues, los lazos de sujeción señorial — con independencia de su ubicación territorial - eran los elementos constitutivos del mapa geo-político del Centro de México y de otras amplias áreas de Mesoamérica en vísperas de la Conquista ${ }^{25}$. Resulta altamente probable que estos nuevos presupuestos teóricos influyeran notablemente al trabajo de F. F. Berdan et alii cuando se concluye que Molango de Escamilla es un candidato fiable al Mollanco de los registros tributarios del siglo XVI' ${ }^{26}$, propuesta a la que nos adherimos claramente. A continuación, analizaremos las diferentes sujeciones políticas a las cuales el señorío de Molango se vio presionado en la época prehispánica tardía.

\section{MOLANGO Y SU SUBORDINACIÓN A ENTIDADES POLÍTICAS MAYORES}

\section{- Metztitlán}

Otomíes, chichimecas, nahuas, olmeca-xicallancas, tepehuas, huaxtecas y totonacas parecen haber sido los principales grupos étnicos a través de los cua-

22 Carrasco, 1996: 516-520.

23 Rojas, en prensa.

24 Hassig, 1985: 92.

25 Rojas, 32 (Madrid, 2002): 121-124; LIV/3 (México DF, 2005): 688. Smith, 2003b.

26 Berdan et alii, 1996: 349, fig. A4-26. 
les se asentaría la identidad metzca en el Posclásico Tardío ${ }^{27}$. Esta misma multi-etnicidad podría ayudarnos a explicar ciertos patrones económicos y políticos que hallamos en localidades sujetas al señorío de Metztitlán, tales como Molango. En la Suma de Visitas de 1554, se especifica que Molango tenía 22 estancias: Huizotla, Tenango, Zacuala, Naupan, Aytic, Huiznopala, Acayucan, Chixhuacan, Coachichilco, Aoztopila, Acatepeque, Ixcatlan, Malila, Tula, Culustlan, Ichtlahuaco, Atla, Cipacictlan, Tethtipan, Acayutla, Texupeche y Tanchaco $^{28}$. En nuestra investigación tan sólo hemos podido identificar 12 de estas 22 estancias (Fig. 2). Ixcatlan y Zuacala (= Zacualtipán) están localizadas en nichos ecológicos muy cercanos a la Vega de Metztitlán, es decir, tienen características climáticas de tipo sub-tropical. En estas estancias se podían haber realizado cultivos de tipo macro-térmico (como el algodón); de hecho el análisis etimológico de Ixcatlan («abundacia de algodón», «lugar donde crece el algodón») parece apuntar hacia esa dirección. En Zacuala-Zacualtipán la explotación minera del caolín - utilizado como pasta en la producción cerámicay el trabajo de la obsidiana parecen haber constituido ramos ocupacionales importantes durante la época virreinal temprana ${ }^{29}$, actividades que tuvieron un claro antecedente prehispánico. De hecho, los análisis por activación neutrónica sobre diferentes fragmentos de utensilios de obsidiana usados en la Costa del Golfo en la época prehispánica confirman un significativo porcentaje procedente del afloramiento localizado en Zacualtipán. Es más, la obsidiana de Zacualtipán també se llegó a distribuir en cantidades mínimas en sitios tan lejanos como Chichén Itzá $(0,6 \%)$, Dzibilchaltún $(0,2 \%)$, El Petén $(0,9 \%)$, Chiapas $(0,1 \%)$ y el Xoconochco $(0,5-0,7 \%)$ desde el Clásico Temprano al Posclásico Tardío (c. 100-1500 d.C.) ${ }^{30}$. Por su parte, las estancias de Tenango, Naupan, Acayutla, Huiznopala, Ichtlahuaco, Acayucan, Acatepeque, Malila, Tula y Texupeche se ubican en un piso medioambiental de tierra fría en la sierra. Es muy posible que esta zona haya proveído de madera, caza, pieles de animales y productos agrícolas de cultivo meso o micro-térmico (chía, huauhtli, etc.) a la cabecera de Molango. Lo sugerente de este modelo de explotación económica del territorio es el control de diversos pisos ecológicos. Este fenómeno se halla documentado de igual forma en las poblaciones de Culhuacán, Mexicaltzingo, Iztacalco e Iztapalapa en el Valle de México, así como en el área de los Andes Centrales ${ }^{31}$. Además, las estancias de la sierra parecen mostrar pobla-

27 Lorenzo, 2001: 27.

28 Paso y Troncoso, 1905: 145, citado en Lorenzo, 2001: 150.

29 Ruiz de la Barrera, 2000: 37.

30 Jiménez et alii, vol. V/3 (Monterrey, 2002): 352-353. Nelson, 2004.

31 Carrasco, 1996: 56. Murra, 1975. 
ción étnicamente con más afinidades con los grupos otomíes, tepehuas y huaxtecos y las ubicadas en la Vega de Metztitlán con poblaciones nahuas-otomíes. Resulta muy poco probable que en los escasos treinta años transcurridos desde la elaboración de la Suma de Visitas en 1554 a la conquista de Metztitlán en 1524 el antiguo patrón de dominios territoriales de la cabecera de Molango se haya modificado sustancialmente. Ello sugiere que los señores o tlahtoqueh de Molango de la época prehispánica percibieron rentas en bienes y servicios de una población de base multiétnica dispersa en diferentes pisos medioambientales, patrón bastante común en los altepemeh de Altiplano Central durante el Horizonte Posclásico Tardío ${ }^{32}$. Es comprensible que la elite molanca aceptase la sujeción tributaria impuesta por Metztitlán, teniendo en cuenta que poseía un mínimo de dos estancias en la tierra caliente de la Vega. La vinculación entre los dos señoríos se podría haber conseguido mediante el intercambio mutuo de títulos de propiedad sobre ciertas tierras y cargas tributarias, estableciendo un modelo de entreveramiento territorial ${ }^{33}$.

Figura 2. Distribución territorial de los sujetos del altepetl de Mollanco (ELABORADO POR R. ROVIRA)

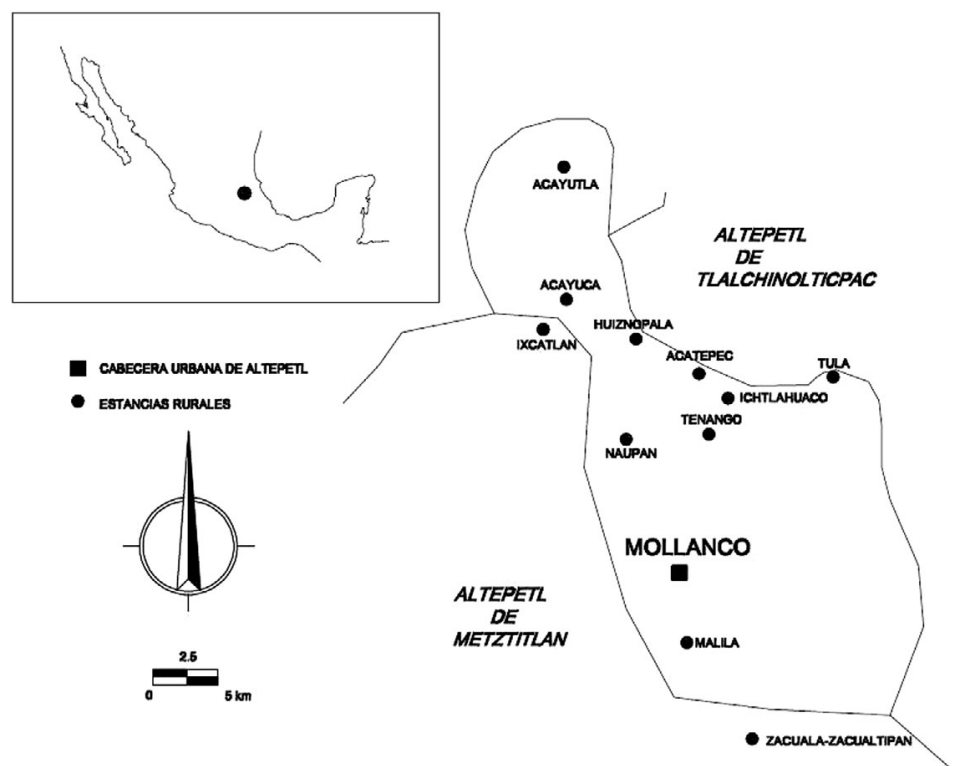

32 Hirth, 2009: 275.

33 Carrasco, ibidem. 


\section{- Huejutla (Huexotlan)}

Sin embargo, contamos con fuertes evidencias documentales de que Molango mantenía muy diversas relaciones sociopolíticas con diferentes entidades con independencia de Metztitlán. Tal parece ser el caso del señorío prehispánico que tuvo su epicentro en la moderna localidad de Huejutla de Reyes (Hidalgo), localizada a escasos 60 kilómetros de Molango. La Relación de Huejutla - fechada del año 1580 - menciona que el señor local Cocoteuhtli había establecido un dominio carismático en su área de influencia en el momento previo a la Conquista:

«... que el señor que ellos conocieron postrero en su gentilidad fue un cacique que se llama(ba) Cocotectli [Cocoteuhtli] que después se bapticó y se llamó Don Domingo, y era muy gran principal; y que le daban todos los yndios de las sementeras que le cogían de mayz, chili, algodón y frisoles, gallinas y mantas, y de todo lo que tenyan le daban abundantemente y no por bía de tasaçión, y que de muchos pueblos de biente, treinta leguas de aqui le benian a traer muchos presentes destas cosas arriba contenidas, por que después de tenerle por cacique les hacía entender que él era, tenya poder para hacer llover y que diese frutos la tierra; y así benían de muchas partes, si tenían falta de agua, a saber quando abía de llober y que le rrespondía que día abía de llober y que sembrasen, y dizen que acertaba en todo por que hablaba con el demonyo, y que a esta causa le tenyan gran respeto y le obedecian en todo lo que les mandaba, asi en guerras como en todo lo que quería.»34

Dicha evidencia documental demuestra que este tipo de servicios carismáticos eran retribuidos a Cocoteuhtli con la concesión voluntaria de maíz, frijoles, chiles, guajolotes, algodón y textiles finos o mantas. Es más, si el control de Cocoteuhtli se extendía un mínimo de 20 leguas a la redonda de Huejutla (es decir, a un radio de 100-110 kilómetros aproximadamente) es muy probable que los señores de Molango le debiesen algún tipo de obediencia o vasallaje que no implicaría necesariamente la donación de una carga tributaria regular. Ello estaría acorde con las argumentaciones de Frederick Hicks en torno a las relaciones existentes entre Temazcalapa y México-Tenochtitlan, por las cuales en el Centro de México del Horizonte Posclásico era usual que los maceguales y ciertos principales reconocieran la supremacía de un señor mayor. Tal reconocimiento se efectuaba en base a una hegemonía en el carisma personal del propio tlahtoani, centrado en sus dotes como benefactor, protector de la comunidad y oráculo o adivino (tlaciuhqui) ${ }^{35}$.

34 Papeles de la Nueva España (PNE), Relación de Uexutla de Hidalgo [1580], 1979 [1890]: 187.

35 Hicks, 1991: 199-202. 
El tipo de relaciones de dependencia señorial que se establecían se concretaban en la donación voluntaria de ciertos presentes (gift-givings) que estimulaban una creciente generosidad competitiva entre las elites ${ }^{36}$. Resulta probable que una situación similar se estableciese entre el tlahtoani de Molango y el señor Cocoteuhtli de Huejutla. El carisma personal de este señor local podía haber mostrado ciertas peculiaridades atrayentes para las elites molancah, así como el hecho de que él fuera la máxima autoridad competente en la administración del «mercado internacional» que Huejutla albergaba ${ }^{37}$. Tenemos conocimiento de que tratar en este tipo de espacios comerciales implicaba pagar el correspondiente presente de vasallaje - tlacallaquilli- y tasa mercantil o alcabala — tianquiztequitl — al tlahtoani local ${ }^{38}$. Es más, creemos que un aspecto primordial para entender la existencia de tales interacciones políticas entre Molango y Huejutla es el hecho de que este último señorío mantenía conflictos armados periódicos con otras localidades sujetas a Metztitlán — como Huazalingo y Tlachinoltícpac - pero no con el primero ${ }^{39}$. Por otra parte, el señorío de Huejutla aparece en el Códice Mendocino conjuntamente a Molango en la provincia tributaria de Tziuhcóac. Sin embargo, resulta más probable que Huejutla mantuviera algún tipo de vinculación con la Triple Alianza en calidad de cliente ${ }^{40}$, puesto que, como discutiremos con posterioridad, constituía un importante núcleo de encuentro e intercambio comercial entre las tierras altas y las tierras bajas del noreste de Mesoamérica.

\section{- Imperio de la Triple Alianza (México-Tenochtitlan, Texcoco y Tlacopan)}

Como hemos aclarado con anterioridad, Molango aparece en diferentes registros tributarios de la Triple Alianza, ya sea tributando directamente a México-Tenochtitlan a través de la red tributaria de Tziuhcóac ${ }^{41}$ o también sujeta al pago de bienes y servicios a Texcoco y Tlacopan ${ }^{42}$ (Fig. 3).

36 Clark y Blake, 1994: 25.

37 Berdan et alii, 1996: 293. Smith y Berdan (eds.), 2003.

38 Carrasco y Broda (eds.), 1978: 55.

39 PNE, Relación de Uexutla de Hidalgo [1580], 1979 [1890]: 188-189.

40 Smith, 1996: 149.

41 La localización de la cabecera de Tziuhcóac ha sido altamente controvertida. En la actualidad se asume que se ubicó en el yacimiento arqueológico de Mesa de Cacahuatenco (Ixhuatlán de Madero, Veracruz). Para ampliar tal cuestión se recomienda la lectura de G. Stresser-Péan, Los Lienzos de Acaxochitlán (Hidalgo). Publicaciones del Gobierno del Estado de Hidalgo et alii, México DF, 1998.

42 Motolinía, 1971 [1540]. Carrasco, 1996: 516, 520. 
Figura 3. CalpixCayotl (PROVInCIA tributaria) de TZiuhcóaC

(ELABORADO POR R. ROVIRA)

\begin{tabular}{|l|l|l|l|}
\hline \multicolumn{4}{|c|}{ CALPIXCAYOTL DE TZIUHCÓAC } \\
\hline \multicolumn{1}{|c|}{$\begin{array}{c}\text { Señoríos } \\
\text { sujetos }\end{array}$} & \multicolumn{1}{|c|}{ Códice Mendocino } & $\begin{array}{l}\text { Memoriales } \\
\text { (Motolinía) }\end{array}$ & $\begin{array}{l}\text { Obras Históricas } \\
\text { (Ixtlilxóchitl) }\end{array}$ \\
\hline $\begin{array}{l}\text { Tziuhcóac } \\
\text { Cozcateuhtlan } \\
\text { Ichcatlan } \\
\text { Xocoyohcan } \\
\text { MOLANGO }\end{array}$ & $\begin{array}{l}400 \text { fardos de chile } \\
\text { Indumentaria militar y armamento } \\
400 \text { mantas con cenefas } \\
400 \text { máxtlatl } \\
400 \text { huipiles } \\
800 \text { mantas de cuatro manos }\end{array}$ & $\begin{array}{l}\text { téquitl a Texcoco vivos } \\
\text { pieles de ciervo } \\
\text { plumas preciosas } \\
\text { loros }\end{array}$ \\
\end{tabular}

El privilegiado status jurídico del que disfrutó Molango en el marco de las relaciones de sujeción clientelar de la Triple Alianza pudo haberse manifestado en el hecho de que la autoridad de su tlahtoani fuese mantenida tras la conquista de estos territorios durante el reinado de Ahuízotl (1486-1502) ${ }^{43}$, aunque bajo la supervisión de un calpixqui ${ }^{44}$. Es más, su importancia en el panorama geo-político y económico del norte del México Central pudo afianzarse durante los primeros momentos de la época virreinal temprana. Tal y como José Lameiras remarcó:

La organización política y religiosa colonial mucho caso hizo en general de la antigua organización política indigena. Se puede decir que los pueblos distinguidos por el régimen virreinal habian sido importantes en la antigüedad. En Metztitlán lo fueron sobre otros la propia cabecera, Molango, Huazalingo, Xochicoatlán, Zacualtipan, Tianquistengo y Yahualica ${ }^{45}$.

Hemos de mencionar que hacia 1580 el convento agustino de Molango se había convertido en el foco espiritual y cultural más importante de la serranía de Metztitlán ${ }^{46}$. Es más, contamos con evidencias documentales inéditas que sugieren que la orden de los agustinos afincada en Molango desde la década de 1530 poseía en propiedad una amalgama muy elevada de bienes inmuebles, tal y como reflejan las actas de adquisición de un molino azucarero y de tierras en la localidad huaxteca de Tamazunchale a inicios del siglo XVII ${ }^{47}$. Por otra

43 Motolinía, 1971 [1540]: 396.

44 Ixtlilxóchitl, 1965 [1615], vol. 2: 196.

45 Lameiras, 1969: 139.

46 Ruiz de la Barrera, 2000: 67-68.

47 Un trapiche, acordado. Personas que reciben: reverendos religiosos agustinos de Mo- 
parte, la antigua elite indígena local fue respetada y fidelizada en el nuevo panorama del Virreinato. Hacia 1650, Marcos de Tapia, principal y cacique de Molango, recibió del virrey G. Sarmiento de Sotomayor el mandamiento pertinente para percibir trabajo comunitario (tequitl) por parte de ciertos maceguales ${ }^{48}$. Todos estos datos refuerzan la idea por la cual Molango mantuvo una cierta continuidad de poder a nivel local y regional en el panorama del México Central con posterioridad a la Conquista.

Figura 4. Mapa geo-político del Centro de México durante el Horizonte Posclásico Tardío atendiendo a las demarcaciones presentes en la Matrícula de TRibutos y eL Códice MENDocino (elaborado por R. Rovira)

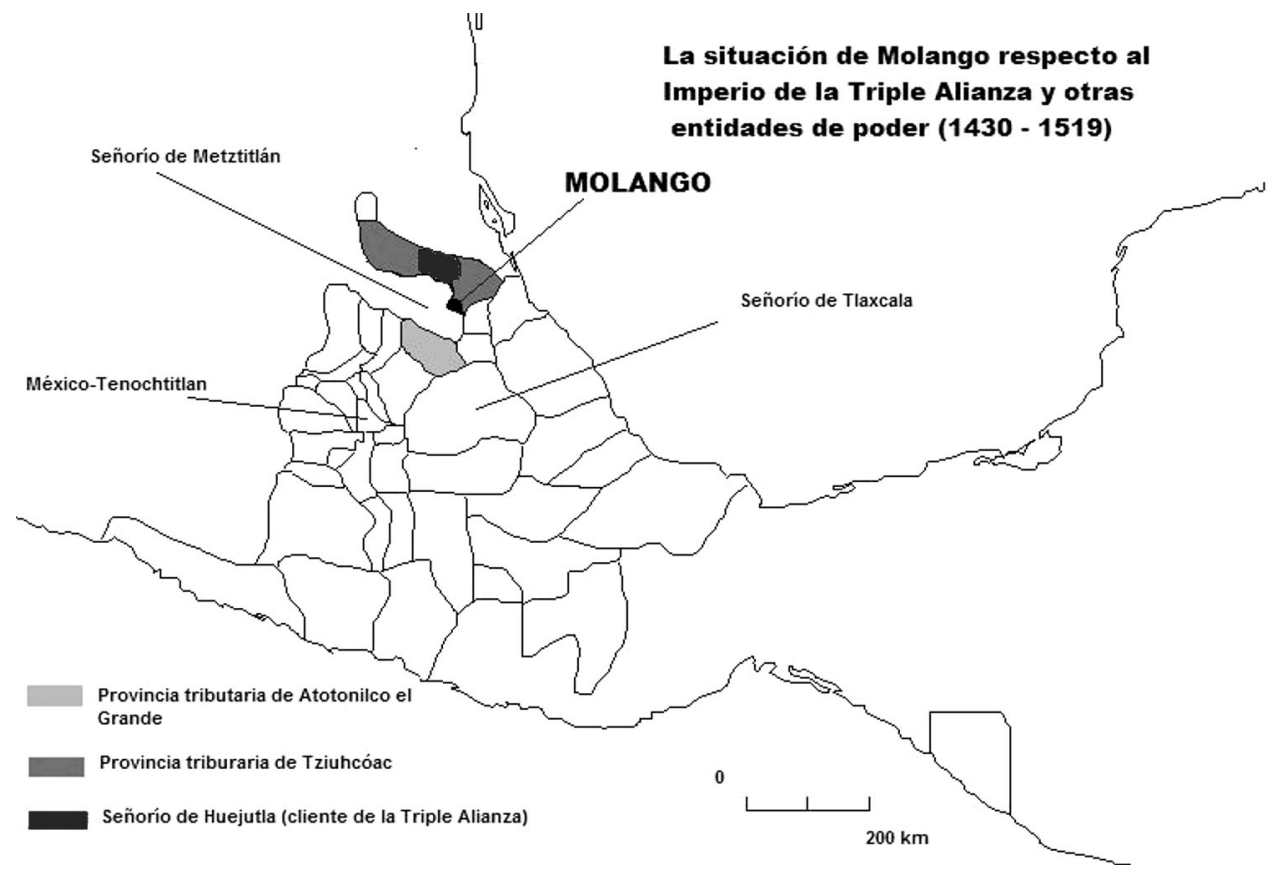

lango. Tamasunchal. 1602, Archivo General de la Nación (AGN), México DF (México), Mercedes, volumen 23: 1v.

$48 \mathrm{Su}$ excelencia aprueba el mandamiento inserto para que [a] Marcos de Tapia, cacique de Molango, se le repartan tequios... 1648 (AGN), México DF (México), Indios, vol. 15, exp. 93. 


\section{ELITES, CASAS SEÑORIALES Y ESTADO HEGEMÓNICO}

¿Resulta comprensible el comportamiento de las elites locales de Molango durante el Horizonte Posclásico Tardío? ¿Qué tipo de arena política pudo promover estas complejas relaciones de sujeción tributaria que hemos establecido? Es probable que la clave a estas interrogaciones se encuentre en la propia concepción que los antiguos mesoamericanos atribuían a la praxis de la autoridad y del poder.

La existencia de un origen multiétnico enfatizó la adscripción de un señor a otro por relaciones de filiación etnolingüística o de parentesco. Esto conllevaría la puesta en práctica de una multiplicidad de formas de subordinación política y de la creación de grupos segmentarios de poder ${ }^{49}$. Es más, se favorecía el surgimiento tanto de diversas facciones políticas ${ }^{50}$ como de una constante variación en las relaciones de dependencia señorial -o Personenverbandpara afianzar los intereses locales ${ }^{51}$.

Nos ha parecido atractivo y adecuado relacionar la adhesión que ciertas elites prehispánicas mostraron hacia diferentes entidades de poder de manera multilateral y ambivalente con el modelo de maison o casa señorial ${ }^{52}$. Las relaciones de poder internas en las casas señoriales se expresaban mediante un lenguaje parental que iba más allá de la consanguinidad y la afinidad, puesto que las fórmulas de patrón-cliente solían ser los mecanismos de integración más usuales ${ }^{53}$. En este sentido, los señores eran considerados «padres» o «hijos mayores» y podían mantener muy diversos grados de interacción política con otros «hermanos mayores»o «hermanos menores» ${ }^{54}$. Además, el tecpan o teccalli (etim., «casa del señor») era considerado un verdadero «cuerpo» arquitectónico ${ }^{55}$, un receptáculo doméstico diseñado para albergar a los miembros de la familia noble - la «cabeza» de la casa-, así como a sus círculos señoriales más próximos - es decir, sus «extremidades»—. Todas estas consideraciones implicaban que en la Mesoamérica Posclásica un mismo señor podía tributar a diferentes casas señoriales al mismo tiempo, una práctica nada ajena

49 Southall, 1991: 89

50 Brumfiel y Fox (eds.), 1994. Bueno, 2004: 653-655.

51 Hoekstra, 1990: 70-76. Ouweneel y Hoekstra, 2003. Rojas, 32 (Madrid, 2002): 121-122.

52 Lévi-Strauss, 1969.

53 Carrasco, 1976: 21-22. Chance, 102/3 (Arlington [Virginia, EUA], 2000). Gillespie, 102/3 (Arlington [Virginia, EUA], 2000): 475-477.

54 León-Portilla, 1992: 142. López Austin y López Luján, 1999: 42.

55 Véase la definición y su aplicabilidad a los ámbitos residenciales de las elites prehispánicas en Houston y Cummins, 2004: 365-366. 
al desarrollo sociopolítico que hallamos en otras sociedades pre-capitalistas, como la Europa Occidental durante el Alto Medioevo. En este sentido tenemos conocimiento de que el conde Sunifred de la Casa de Barcelona percibía en el siglo IX tributos, tanto en bienes como en servicios personales, de figuras señoriales menores sujetas a él por vinculaciones clientelares y, al mismo tiempo, él mismo ofrecía prestaciones administrativas a la familia real carolingia $^{56}$. Una correspondencia homotaxial con este caso de la Cataluña feudal la podríamos establecer con el señorío tepaneca de Cuauhtitlán, los tlahtoqueh del cual, además de pagar tributo a Tlacopan, transferían bienes y servicios a Tenochtitlan, Tlatelolco, Colhuacán, Ixtapalapa, Mexicaltzingo, Azcapotzalco y Texcoco ${ }^{57}$.

La multi-dependencia de poderes que podía mostrar un mismo señorío en Mesoamérica encaja claramente con el modelo sociopolítico postulado por el etnohistoriador Ross Hassig al cual nos hemos referido con anterioridad: el Estado hegemónico. Es más, un componente inherente a este tipo de instituciones basadas estrictamente en los lazos de lealtad personal entre señores es una clara ineficiencia administrativa, así como una incapacidad de mantener centralizados los diferentes focos de poder y autoridad que cada casa señorial genera. Merece la pena mencionar que Andrés Ciudad apunta a similares aseveraciones cuando analiza el sistema de gobierno del señorío chontal de Acalán hacia el año $1525^{58}$.

En resumen, la mayoría de evidencias etnohistóricas que hemos aportado respaldan la idea de que en la Mesoamérica del Posclásico Tardío las redes de dominación señorial constituían los verdaderos ejes axiales a través de los cuales se articulaba la vida política de los diversos altepemeh. La conclusión inmediata que se genera atendiendo a los datos que hemos expuesto es que el señorío de Molango evidenció perfectamente situaciones de sujeción clientelar tanto con Metztitlán como con Huejutla y con el Imperio de la Triple Alianza de manera simultánea, alterando constantemente el juego de alianzas políticas. Dicha situación se podría hallar en estrecha relación con la «alianza entre elites» a la que Michael E. Smith apela cuando analiza la organización política del México Central durante el Horizonte Posclásico Tardío ${ }^{59}$. Con respecto a este «pacto» entre diferentes casas señoriales centro-mexicanas, el mismo autor nos comenta juntamente con Frances F. Berdan lo siguiente:

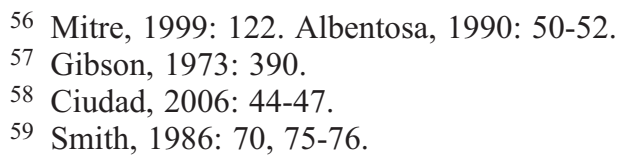


«(...) The Central Mexican nobility achieved a true commonality of interest that transcended political boundaries. Noble lineages from distant city-states were linked by marriage alliances, exchange of luxury goods, restricted cultural codes like writing and the calendar, and common participation in periodic rituals of solidarity and consumption. These bonds of interaction were built upon a foundation of commonality of the nobles' control over land, labor, and government. This Central Mexican elite class was not unique in Postclassic Mesoamerica, and Roland Spores (1984) describes the same phenomenon among the Mixteca.» ${ }^{60}$

[La nobleza del Centro de México logró un verdadero interés común que trascendía las fronteras políticas. Los linajes nobiliarios de ciudades-estado lejanas [entre sí] estaban vinculados por alianzas matrimoniales, intercambio de bienes de prestigio, códigos culturales restringidos como la escritura o el calendario y la participación común en rituales periódicos de solidaridad y consumo. Estos lazos de interacción fueron construidos en pos de lo común de los nobles [en cuanto] al control sobre la tierra, el trabajo y el gobierno. Esta clase elitista del Centro de México no era única en la Mesoamérica Posclásica y Roland Spores (1984) describe el mismo fenómeno entre los mixtecas.]

(traducido por el autor)

En el siguiente apartado indagamos dos factores clave para entender la existencia de un marco de cooperación común entre las elites locales y las elites hegemónicas en esta área de Mesoamérica: la sal y las redes de comercio a larga distancia.

\section{SAL, RUTAS DE INTERCAMBIO Y CENTROS DE COMERCIO INTERNACIONAL EN LA Sierra de MetzTitlán y LA HuAXTECA}

Tenemos conocimiento de que la falta de aportes de sodio procedentes de un elevado consumo de carne animal se suplió necesariamente en Mesoamérica mediante la ingestión de altas cantidades de sal. De hecho, la sal fue uno de los productos de subsistencia que más ampliamente se distribuyeron en los circuitos comerciales de la Mesoamérica Posclásica ${ }^{61}$. Si bien es cierto que el Centro de México contaba con las salinas del lago Texcoco ${ }^{62}$ y con ciertos afloramientos de tequixquitl — NaCI, o cloruro de sodio - en el área NE del valle de Puebla-Tlaxcala, siempre contó con problemas para su abastecimiento. Hemos de recordar que el Altiplano Central fue una región que posiblemente llegó a albergar más de 4 millones de personas en el Posclásico Tardío. Los principales focos de extracción salinera procurarían este recurso a los nú-

60 Smith y Berdan, 1996: 211.

61 Andrews, 1983: 41. Berdan et alii, 2003.

62 Parsons, 1994: 43-44. 
cleos demográficos más importantes y urbanizados, tales como el Valle de México. De esta forma, muchas regiones y localidades del México Central podrían haber quedado desabastecidas de sal.

Sin embargo, la sal fue un bien de subsistencia que circuló profusamente en el área del norte del Centro de México. Disponemos de datos etnohistóricos que confirman que la sal que se consumía en la Huaxteca y Metztitlán se importaba directamente de las salinas de la cuenca baja del río Pánuco o de las lejanas regiones de la costa de Campeche:

...porque en este pueblo [Huejutla de Reyes, Hidalgo] es la contratación de sal de toda esta tierra, aunque viene de muy lejos que viene de Campech[e], y otras vezes viene de Tampico quando alli lo ay ${ }^{63}$.

Huejutla fue el principal centro comercial especializado en la distribución de sal en el área de la Huaxteca y buena parte de los territorios del norte del México Central durante el Horizonte Posclásico Tardío. Su mercado internacional albergaba a diferentes tipos de tratantes y comerciantes procedentes de la Cuenca de México, el valle poblano-tlaxcalteca y las zonas totonaca y tepehua ${ }^{64}$. Constituía, pues, un nodo importante de conexión entre las tierras bajas del Golfo de México y las estribaciones de la Sierra Madre Oriental ${ }^{65}$. Sin embargo, disponemos de datos muy fragmentarios sobre la incorporación del señorío de Huejutla al Imperio de la Triple Alianza, lo que ha suscitado la duda en torno a las condiciones en las cuales se efectuó su posible conquista y sometimiento. Fray Juan de Torquemada menciona la presencia permanente de calpixqueh mexicah en esta ciudad ${ }^{66}$, lo que sugiere la existencia de una sujeción tributaria regular. No obstante, resulta probable que estos oficiales residiesen en Huejutla en calidad de invitados diplomáticos, cuyas actividades se encaminarían a favorecer el comercio franco de los pochtecah en la feria internacional que allí se celebraba cada 20 días. Tal y como Michael E. Smith ha argumentado, Huejutla se insertó en las redes políticas de la Triple Alianza como señorío amigo y cliente de los tlahtoqueh del Valle de México ${ }^{67}$.

Esta estrategia política facilitó que Huejutla continuase sin dificultades su actividad comercial. La sal que importaba de las tierras bajas normalmente procedía del área de Campeche-Tabasco, puesto que las actividades extractivas realizadas en las cercanas salinas de Tampico, Chila, Pánuco, Tanchoy y

63 PNE, Relación de Uexutla de Hidalgo [1580], 1979 [1890]: 186.

64 Smith, 1996: 149.

65 Robles, 1 (San Juan de Puerto Rico, 2004): 71-72.

66 Torquemada, 1969 [1615], vol. 1: 193.

67 Smith, 1996: 141-149. 
Figura 5. Situación de Molango en las redes de comercio a larga distancia en Mesoamérica durante el Horizonte Posclásico Tardío (elaborado por R. Rovira)

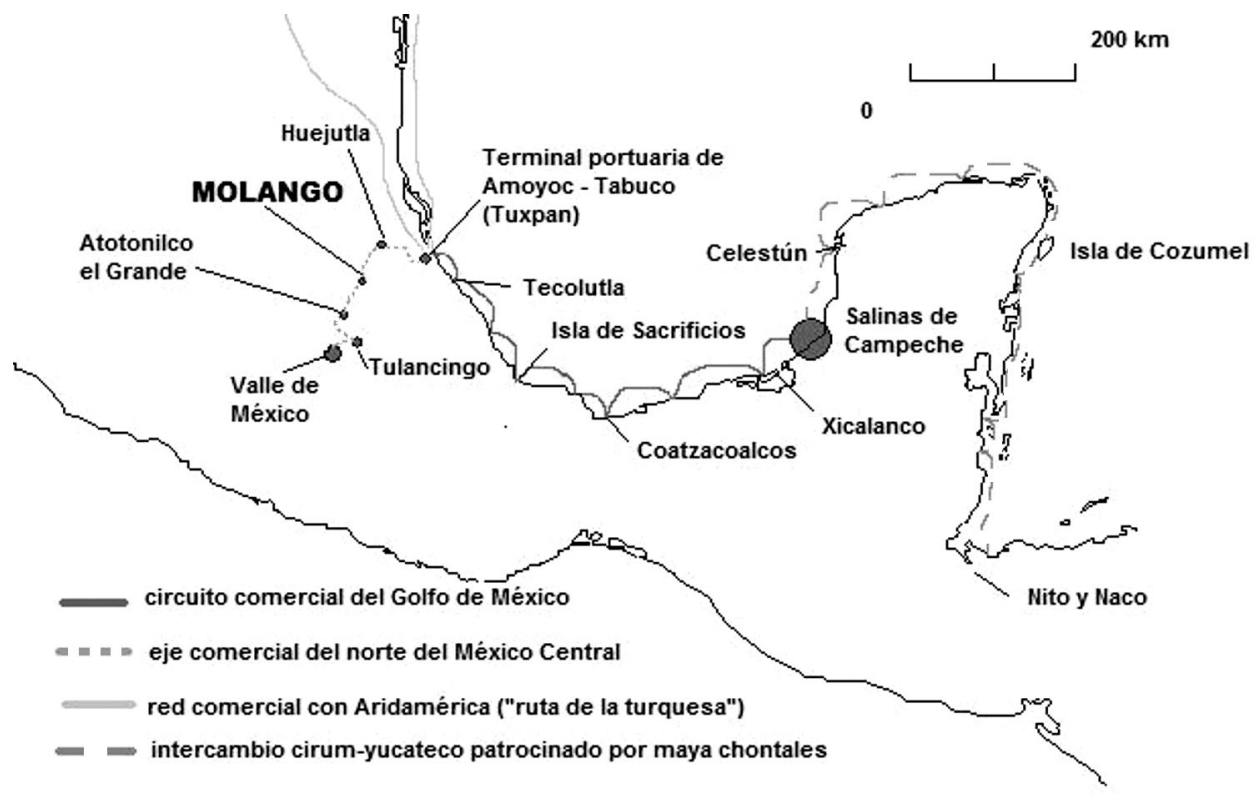

Cuymatlán dependían en un alto grado de las perturbaciones climáticas que provocaban frecuentes inundaciones en la cuenca baja del río Pánuco ${ }^{68}$. Merece la pena mencionar que en Huejutla, juntamente con la sal, probablemente se comercializaran otros productos típicos del intercambio a larga distancia auspiciado por los mayas-chontales de Campeche: orfebrería de oro y cobre procedente de América Central, plumas preciosas, objetos de piedra verde, cacao, miel, cera y pescado. La terminal portuaria de Amoyoc-Tabuco, en el vecino señorío costeño de Tuxpan, constituía el centro neurálgico donde convergían las redes comerciales a larga distancia más importantes del noreste de Mesoamérica (Fig. 5). Aparte de las claras conexiones que el trato de la sal confería a Huejutla con el comercio huaxteco y maya-chontal, este floreciente centro mercantil mantenía complejos intercambios basados en el maíz y otros productos agrícolas locales (como la raíz denominada quequexquitl) con Metztitlán y Tulancingo. José Lameiras se refería a este fenómeno de la siguiente manera:

68 Andrews, 1983: 49-50. 
Los productos que más activaban el comercio hacia Metztitlán o desde él eran en orden de importancia el algodón, y los productos derivados de él, el maíz, la sal y el pescado; otros productos tales como frutos, pieles, alumbre y liquidámbar fueron importantes sin llegar a ser los primeros. Es posible que todo un sistema de mercados serranos se haya establecido para el tráfico de mercancías procedentes de la costa; las guerras y la penetración extranjera al territorio desquiciaban sensiblemente el sistema ${ }^{69}$.

El sistema de mercados serranos a la que J. Lameiras aludía indudablemente implica plantearnos el papel de Molango en las redes de intercambio a larga distancia de la Mesoamérica Posclásica. Molango constituyó un importante nodo de comunicaciones que garantizó el tránsito de comerciantes y productos en la Huaxteca, la serranía de Metztitlán y el valle de Tulancingo durante todo el Virreinato ${ }^{70}$. Dicho monopolio tan sólo peligró a finales del siglo XVIII cuando, por cuestiones administrativas, se intentó modificar la tradicional ruta Ciudad de México-Tulancingo-Metztitlán-Molango-Huejutla-Tuxpan-Pánuco. En ese momento y tal como venían haciendo desde la época prehispánica, las autoridades de Molango «adujeron uno y mil pretextos para evitarlo, puesto que en modo alguno les beneficiaba» ${ }^{71}$.

\section{SUMARIO Y CONCLUSIONES FINALES}

Mesoamérica en la época prehispánica tardía había alcanzado una considerable madurez en el desarrollo de complejas rutas de comunicación y de intercambio económico que favorecían la circulación de una gran cantidad de productos tanto de subsistencia como de prestigio. Podemos afirmar que la zona del norte del México Central no fue ajena a este fenómeno y participó de manera activa en esta dinámica.

Como hemos expuesto en este trabajo académico, el señorío de Molango jugó un papel crucial como garante de las vías comerciales que conectaban la Huaxteca y la Sierra de Metztitlán con el valle de Tulancingo. Dicho monopolio fue posible gracias a la inteligente política de sujeción tributaria a entidades políticas hegemónicas que sus tlahtoqueh tejieron durante el Horizonte

69 Lameiras, 1969: 128-129.

70 Ochoa y Pérez Zevallos, 2001. Lameiras, 1969: 123. Ruiz de la Barrera, 2000. Cabe remarcar que el sistema monetario que las fuentes etnohistóricas determinan para esta zona septentrional del México Central se base fundamentalmente en el uso intensivo de mantas locales denominadas patolquachtli. No hallamos referencias explícitas a la utilización de granos de cacao como se halla ampliamente documentada en la Cuenca de México y el valle poblano-tlaxcalteca para el Posclásico Tardío y el Virreinato Temprano.

71 Ochoa, 1996: 249. 
Posclásico Tardío. La dependencia a Metztitlán favoreció el control de las estancias localizadas en los nichos ecológicos de tipo sub-tropical de la Vega, susceptibles de ser explotadas mediante el cultivo del algodón. Por otra parte, las relaciones de vasallaje hacia el señorío de Huejutla y el Imperio de la Triple Alianza se debieron a la intención de garantizar la continuidad en el control de las rutas de comunicación y el monopolio del intercambio comercial de la sal y la obsidiana en la Sierra de Metztitlán.

La estrategia política que hemos analizado para el señorío de Molango pone de relieve la tónica general que caracterizó a los altepemeh centro-mexicanos durante la época prehispánica tardía: la sujeción tributaria era entendida como un «pacto tácito» que favorecía el mantenimiento de elevadas cuotas de poder a nivel local y regional. Sobre estas mismas bases se cimentarían las futuras relaciones de poder durante el Virreinato.

\section{Agradecimientos Personales}

Desearía expresar mi más sincera gratitud a una serie de profesionales académicos que han contribuido de muy diversas formas a que este trabajo salga a la luz. En primer lugar, al Dr. Francisco L. Jiménez Abollado y a la Dra. Verenyce Cipatli Ramírez (Universidad Autónoma del Estado de Hidalgo, México) por sus asesorías y observaciones durante mi estancia de investigación en México durante el año 2006. A la Dra. Meritxell Tous i Mata (Universitat de Barcelona), así como al Dr. José Luis de Rojas Gutiérrez de Gandarilla y al Dr. Andrés Ciudad Ruiz (Universidad Complutense de Madrid) agradecerles sus acertadas apreciaciones en torno a cuestiones de metodología etnohistórica.

\section{REFERENCIAS MENCIONADAS}

\section{Fuentes}

PNE - Papeles de la Nueva España. Francisco del Paso y Troncoso (ed.). Madrid y México DF., 1979 [1890].

AGN - Archivo General de la Nación. México DF., México.

\section{Bibliografia}

Acuña, René (ed.), Relaciones geográficas del siglo XVI, México DF, Publicaciones UNAM, 1986.

Albentosa, Luis Miguel, Nou atlas històric, geogràfic i econòmic de Catalunya, Barcelona, Editorial Ibis, 1990. 
Álvarez Palma, Ana María y Gianfranco Casiano, Proyecto Vega de Metztitlán, México DF, ENAH, en vigor.

Andrews, Anthony P., Maya Salt Production and Trade, Tucson, University of Arizona Press, 1983.

Artigas, Juan, Metztitlán, Hidalgo: arquitectura del siglo XVI, México DF, Publicaciones UNAM-EH, 1996.

Barlow, Robert H., The Extent of the Empire of the Culhua Mexica, Berkeley, University of California Press, 1949.

Berdan, Frances F. et alii (eds.), Aztec Imperial Strategies, Washington, Dumbarton Oaks, 1996.

Berdan, Frances F. et alii, «An International Economy», The Postclassic Mesoamerican World, Michael E. Smith y Frances F. Berdan (eds.), Salt Lake City, University of Utah Press, 2003: 96-108.

Berdan, Frances F. y Michael E. Smith, «Imperial Strategies and Core-Periphery Relations», Aztec Imperial Strategies, Frances F. Berdan et alii (eds.), Washington, Dumbarton Oaks, 1996: 209-218.

Berdan, Frances F. y Michael E. Smith, «El sistema mundial mesoamericano posclásico», Relaciones, vol. XXV/099 (Zamora [México], 2004): 17-77.

Brumfiel, Elizabeth y John. Fox (eds.), Factional competition and political development in the New World, Cambridge, Cambridge University Press, 1994.

Bueno, Isabel: «La importancia del faccionalismo en la política mesoamericana», Revista de Indias, vol. LXIV/n. 232 (Madrid, 2004): 651-672.

Carrasco, Pedro, «Los linajes nobles del México antiguo», Estratificación social en la Mesoamérica prehispánica, Pedro Carrasco y Johanna Broda (eds.), México DF, SEP-INAH, 1976: 19-36.

Carrasco, Pedro, Estructura político-territorial del Imperio Tenochca. La Triple Alianza de Tenochtitlan, Tetzcoco y Tlacopan, México, FCE-CM, 1996.

Carrasco, Pedro y Johanna Broda (eds.), Economía política e ideología en el México prehispánico, México, Publicaciones INAH, 1978.

Ciudad, Andrés, «El poder del rey y el poder de los nobles mayas en la época del Contacto», Actas del XI Encuentro-Debate América Latina Ayer y Hoy, G. Dalla-Corte et alii (coords.), Barcelona, Universitat de Barcelona, 2006: 39-48.

Clark, John E. y Michael Blake, «The power of prestige: competitive generosity and the emergence of rank societies in Lowland Mesoamerica», Factional Competition and Political Development in the New World, Elizabeth Brumfiel y John F. Fox (eds.), Cambridge, Cambridge University Press, 1994: 17-30.

Contreras, Rita, Indios y encomenderos en Metztitlán (conflicto socioeconómico, 1552-1554), México DF, Tesis de Licenciatura en la ENAH, 1997 
Cortés, Hernán, Cartas de Relación a Carlos V, Madrid, Editorial Dastin, 2000 [1520-1524].

Chance, John K., «The Noble House in Colonial Puebla: Descent, Inheritance, and the Nahua Tradition», American Anthropologist, 102/3 (Arlington [Virginia, EUA], 2000): 485-502.

Davies, Nigel, Los señorios independientes del Imperio Azteca, México DF, Publicaciones INAH, 1968.

Díaz del Castillo, Bernal, Historia verdadera de la conquista de la Nueva España, Madrid, Editorial Castalia, 1999 [1575].

Durán, Diego, Historia de las Indias de la Nueva España e Islas de la Tierra Firme, México DF, Editorial Porrúa, 1971 [1587].

Fernández, Federico y Gustavo Garza, La pintura de la Relación de Metztitlán (1579), en www.monografías.com

Gerhard, Peter, A Guide to the Historical Geography of New Spain, Cambridge, Cambridge University Press, 1972.

Gibson, Charles, The Aztecs under Spanish Rule, 1519-1810, Stanford, Stanford University Press, 1964.

Gillespie, Susan, «Rethinking Ancient Maya Social Organization: Re-placing "Lineage" with "House"», American Anthropologist, 102/3 (Arlington [Virginia, EUA], 2000): 467-484.

Grijalva, Juan de, Crónica de la Orden de N.P.S. Agustín en las provincias de la Nueva España: en cuatro edades desde el año 1533 al de 1592, México DF, Imprenta Victoria, 1926 [1620].

Hassig, Ross, Trade, Tribute, and Transportation. The Sixteenth-Century Political Economy of the Valley of Mexico, Norman, University of Oklahoma Press, 1985.

Hicks, Frederick, «Gift and Tribute: Relations of Dependency in Aztec Mexico», Early State Economics, Henri J. M. Claessen y Peter Van de Velde (eds.), New Brunswick, Transaction Publishers, 1991: 199-213.

Hirth, Kenneth, «Incidential Urbanism. The Structure of the Prehispanic City in Central Mexico», The Ancient City. New Perspectives on Urbanism in the Old and New World, Joyce Marcus y Jeremy A. Sabloff (eds.), Santa Fe (New Mexico), School for Advanced Research Resident Scholar Series, 2009: 273-297.

Hoekstra, Rik, «A Different Way of Thinking: Contrasting Spanish and Indian Social and Economic Views in Central Mexico (1550-1660)», The Indian Community of Colonial Mexico. Fifteen Essays in Land Tenure, Corporate Organization, Ideology, and Village Politics, Arij Ouweenel y Simon Miller (eds.), Amsterdam, Publicaciones del CEDLA, 1990: 60-86. 
Houston, Stephen y David Cummins, «Body, Presence, and Space in Andean and Mesoamerican Rulership», Palaces of the Ancient New World, Susan T. Evans y Joanne Pillsbury (eds.), Washington, Dumbarton Oaks, 2004: 359-398.

Ixtlilxóchitl, Fernando de Alva, Relaciones Históricas, 3 volúmenes, México DF, UNAM-IIH, 1965 [1615].

Jiménez, Luis et alii, «Caracterización por ANN de muestras de yacimientos de obsidiana de la Costa del Golfo», Ciencia UANL, vol. V/3 (Monterrey, 2002): 351-360.

Lameiras, José, Metztitlán: notas para su etnohistoria, México DF, Tesis de Maestría de la ENAH, 1969.

Landa, Diego de, Relación de las cosas de Yucatán, Madrid, Editorial Dastin, 2001 [1566].

León-Portilla, Miguel, The Aztec Image of Self and Society: an Introduction to Nahua Culture, Salt Lake City, University of Utah Press, 1992.

Lévi-Strauss, Claude, Las estructuras elementales del parentesco, Barcelona, Editorial Crítica, 1969.

Lockhart, James, Los nahuas después de la Conquista. Historia social y cultural de la población indígena del México Central, siglos XVI-XVIII, México, FCE, 1999.

López Austin, Alfredo y Leonardo López Luján, Mito y realidad de Zuyuá, México DF, FCE-CM, 1999.

Lorenzo, Ana María del Carmen, Metztitlán, Hidalgo, en el siglo XVI: Economía y Sociedad, México DF, Tesis de Maestría en la FFL-UNAM, 2000.

Mitre, Emilio, Historia de la Edad Media en Occidente, Madrid, Editorial Crítica, 1999.

Motolinía, fray Toribio de Benavente, Memoriales, México DF, UNAM-IIH, 1971 [c.1540].

Muñoz Camargo, Diego, Historia de Tlaxcala, Madrid, Editorial Dastin, 2000 [1585].

Murra, John, Formaciones económicas y políticas del mundo andino, Lima, Instituto de Estudios Peruanos, 1975.

Nelson, Fred W., «El intercambio de obsidiana en las Tierras Bajas Mayas», XVII Simposio de Investigaciones Arqueológicas en Guatemala, Joan Pedro Laporte et alii (eds.), Museo Nacional de Arqueología y Etnología, Guatemala, 2004: 925-935.

Ochoa, Lorenzo, «El orden social, político y económico de la costa del Golfo al momento del Contacto», Mesoamérica y Los Andes, Mayán Cervantes (coord.), México DF, CIESAS, 1996: 229-256.

Ochoa, Lorenzo y Juan Manuel Pérez Zevallos, Aproximación a las rutas de comunicación y comercio en la Huaxteca, XXVI Mesa Redonda de la Sociedad Mexicana de Antropología, Zacatecas, 2001. 
Osborn, W. Smyth, A Community Study of Metztitlán, New Spain (1520-1810), Des Moines, Tesis Doctoral en la Universidad de Iowa, 1970.

Ouweneel, Arij y Rik Hoekstra, Las tierras de los pueblos de indios en el altiplano de México, 1560-1920, Ámsterdam, Publicaciones CEDLA, 2002.

Parsons, Jeffrey R., «Late Postclassic Salt Production and Consumption in the Basin of Mexico: Some Insights from Nexquipayac», Economies and Polities in the Aztec Realm, Mary G. Hodge y Michael E. Smith (eds.), Albany, Institute for Mesoamerican Studies - State University of New York, 1994: 43-72.

Robles, Irizelma, «Del tianquiztli a las plazas: recorrido histórico por los mercados tradicionales de México», Focus III, 1 (San Juan de Puerto Rico, 2004): 67-74.

Rojas, José Luis de, «La organización del Imperio mexica», Revista Española de Antropología Americana, 21 (Madrid, 1991): 145-169.

Rojas, José Luis de, «El Imperio en el México Central en el Postclásico: a vueltas con las fuentes y las ideas», Revista Española de Antropología Americana, 32 (Madrid, 2002): 115-126.

Rojas, José Luis de, «Mesoamérica en el Posclásico: el contexto imprescindible», Historia Mexicana, LIV/3 (México DF, 2005): 677- 695.

Rojas, José Luis de, El Imperio Azteca: historia de una idea. En prensa. Madrid.

Ruiz de la Barrera, Rocío, Breve Historia de Hidalgo, México DF, FCE-CM, 2000.

Smith, Michael E., «The role of social stratification in the Aztec Empire: a view from the provinces», American Anthropologist, 88 (Alington [Virginia, EUA], 1986): 70-91.

Smith, Michael E., «The Strategic Provinces», Aztec Imperial Strategies, Frances F. Berdan et alii (eds.), Washington, Dumbarton Oaks, 1996: 137-150.

Smith, Michael E., The Aztecs. Londres \& New York, Blackwell Publishing, $2003 \mathrm{a}$.

Smith, Michael E., «Small Polities in Postclassic Mesoamerica», The Postclassic Mesoamerican World, Michael E. Smith y Frances F. Berdan (eds.), Salt Lake City, University of Utah Press, 2003b: 35-39.

Smith, Michael E. y Frances F. Berdan (eds.), The Postclassic Mesoamerican World, Salt Lake City, University of Utah Press, 2003.

Southall, Aidan, «The Segmentary State: From the Imaginary to the Material Means of Production», Early State Economies Henry J. Claessen y Pieter Van de Velde (eds.), New Brunswick, Anthropology Series Press, 1991: 75-96.

Torquemada, fray Juan, Monarquía Indiana, 3 volúmenes, México DF, Editorial Porrúa, 1969 [1615].

Fecha de recepción: 2 de marzo de 2009

Fecha de aceptación: 27 de julio de 2009 


\section{LOCAL ELITES AND POLITICAL ECONOMY IN POSTCLASSIC MESOAMERICA: THE CASE OF MOLANGO (SEÑORÍO DE METZTITLAN)}

Political arenas in Late Postclassical Mesoamerica (1350-1521 AD.) were defined by pervasive and continuous fluctuations and changes on lordly loyalty and power subordination dynamics. Thus, local elites might have shown several levels of dependency to different hegemonic polities. The present paper focuses on a case study in the modern Mexican location of Molango de Escamilla (Estado de Hidalgo). Our ethno-historical data suggest Molango - a polity subjected to the dominion of Metztitlan during Late Pre-Columbian times-also shows clear ties with the nearby dominion of Huejutla, as well as with the Empire of the Triple Alliance. We suggest ancient Molango political multi-dependency fits with the evident necessity to maintain control over both strategic economic resources and access to commercial supply networks.

Key words: Local elites, Molango, political economy, obsidian trade, salt trade, Postclassical Mesoamerica world-system. 